\title{
La correspondencia entre J. Maritain y É. Gilson en 1923. Precisiones en torno a la segunda edición de El tomismo
}

\author{
(4) Ceferino P. D. Muñoz \\ Universidad Nacional de Cuyo / CONICET, Argentina. \\ ORCID: 0000-0003-0372-789X \\ Juan Heiremans Correa \\ Universidad Nacional de Cuyo, Argentina \\ ORCID: 0000-0003-4099-2983
}

Recibido el 14 de enero de 2021; aceptado el 23 de marzo de 2021

\begin{abstract}
Resumen
El siguiente escrito muestra el breve pero enjundioso intercambio epistolar entre quizás los dos filósofos cristianos más importantes del siglo XX: Étienne Gilson y Jacques Maritain. Las cartas están centradas en torno a algunas de las tantas temáticas que inquietaron a los tomistas del siglo pasado -la intuición de Dios, el primer objeto de la inteligencia, la función propia del intelecto humano, entre otras- y que aun muestran su plena actualidad en el debate contemporáneo. Ofrecemos la primera traducción al español de las cartas enviadas en el año 1923 -inicio de una fructífera correspondencia entre ambos filósofos-, con ocasión de la publicación de la segunda edición de El tomismo, uno de los libros más emblemáticos de Gilson.
\end{abstract}

PALABRAS CLAVE: CORRESPONDENCIA, GILSON, MARITAIN, EL TOMISMO, SEGUNDA EDICIÓN.

The correspondence between J. Maritain and É. Gilson in 1923. Details on the second edition of The Thomism

\begin{abstract}
The following text shows the brief but substantial epistolary exchange between possibly the two most important Christian philosophers of the 2oth century: Etienne Gilson and Jacques Maritain. The letters are focused on some of the many themes that troubled Thomists in the last century -the intuition of God, the first object of intelligence, the function of the human intellect, among others- and still show their
\end{abstract}


relevance in contemporary debate. We offer the first Spanish translation of the letters sent in 1923 -the beginning of a fruitful correspondence between both philosophers-, in occasion of the publication of the second edition of The Thomism, one of Gilson's most emblematic books.

KEY WORDS: CORRESPONDENCE, GILSON, MARITAIN, THE THOMISM, SECOND EDITION.

\section{Introducción}

La traducción que ofrecemos a continuación se enmarca en un intercambio epistolar de más de 50 años (1923-1971) entre dos prominentes filósofos cristianos como lo fueron Jacques Maritain y Étienne Gilson. ${ }^{1}$ Las epístolas de marras presentan una doble importancia: por un lado, constituyen el primer intercambio registrado de misivas entre ambos autores; y por el otro, en ellas se abordan temas por demás relevantes para el tomismo del siglo XX. Las misivas dan cuenta de los acontecimientos y los temas que se trataron durante ese medio siglo, y en especial de sus movimientos intelectuales y espirituales (Artola, 1995: 181). Como puntos centrales podemos mencionar las discusiones sobre el tomismo, inserto en un contexto de atención más amplio como es el de la filosofía cristiana. Las polémicas que se generaron por aquellos años en torno a esta temática forjaron una amistad intelectual entre ambos autores, la cual resulta fundamental a la hora de entender algunas importantes evoluciones filosóficas y doctrinales en sus obras. Prueba de ello es el contenido de estas dos cartas, que a continuación analizaremos brevemente.

El disparador de este intercambio epistolar fue el envío de Gilson a su colega Maritain de la segunda edición de El tomismo, aparecida en 1922. En esta nueva versión (la primera data de 1919) el autor introdujo importantes cambios en su presentación del sistema tomista, hecho que es reconocido y apreciado por Maritain. Sin embargo, este último le hace varias observaciones críticas. Veamos algunas de ellas:

En primer lugar, en uno de los pasajes de la segunda edición, Gilson afirma lo siguiente en torno a la relación entre intuición, mística y conocimiento de Dios:

El platonismo encontraba en la mística su último logro, y hay que decir que, al contrario, en la medida en que la mística supondría una intuición y un conocimiento directo de Dios por el alma, el tomismo constituye la negación radical de la mística (1922: 235). ${ }^{2}$

Frente a esta tesis, Maritain dirá que estaría parcialmente de acuerdo con que el tomismo sostiene la idea de una "negación radical de la mística", por lo que ve necesario introducir algunas aclaraciones. Así, si bien reconoce que Tomás no suscribe a una intuición natural de Dios por parte del hombre, sí afirma que existe una intuición sobrenatural de Dios, la cual se da en casos particulares: en el raptus profético y en el conocimiento adquirido por el don de la Sabiduría. Es decir que el tomismo acepta de buen grado la existencia de la intuición mística, pero no la sitúa en el orden natural, sino en el sobrenatural. Como veremos en la segunda carta, Gilson reconoce y aprecia estas críticas. Prouvost (1991: 21) indica oportunamente que Gilson modificó el párrafo en cuestión en la tercera edición de El tomismo, en donde escribe que "El platonismo sitúa la mística en la prolongación natural del conocimiento humano; en

\footnotetext{
1 Para la siguiente traducción nos basaremos en la edición de Prouvost, 1991: 16-23.

2 "Le platonisme trouvait dans la mystique son dernier achèvement, et il faut dire au contraire que, dans la mesure où la mys tique supposerait une intuition et une connaissance directe de Dieu par lâme, le thomisme constitue la négation radicale de la mystique".
} 
el tomismo, la mística se agrega y se coordina al conocimiento natural, pero no lo continúa" (1927: 305). ${ }^{3}$

Un segundo punto interesante para remarcar es el referido a la siguiente afirmación de Gilson: "está pues permitido decir que para Santo Tomás la función propia del intelecto humano es la constitución de la ciencia" (1922: 236). Para Maritain tal afirmación debería ser matizada, puesto que hay que hacer una distinción entre el objeto propio del intelecto -la quidditas rei sensibilis- y el fin propio del intelecto, que es especular sobre la esencia divina más que sobre los cuerpos sensibles. Gilson atiende parcialmente tal corrección, ya que acepta la distinción entre objeto y función, pero no llega a afirmar, como sugiere su colega, que el fin propio del intelecto sea especular sobre la esencia divina. Nuevamente Prouvost (1991:23) indica que Gilson incorporó a grandes rasgos esta distinción en la próxima edición de El tomismo:

Santo Tomás, que sitúa en lo sensible el objeto propio del conocimiento humano, no considera que la función más alta de nuestra facultad de conocer consista en estudiarlo. Pues este intelecto, cuyo objeto propio es lo sensible, tiene como función propia sacar de él algo inteligible (1927: 307$){ }^{4}$

Un tercer y último punto en cuestión es el referente a la vida interior de Santo Tomás. Para Maritain, Gilson sostiene que podemos conocer su vida espiritual a partir de su doctrina filosófica y teológica. Por el contrario, Maritain dirá que el Aquinate no dejaba traslucir en sus obras nada de su vida interior, la cual, además, estaba muy por encima del conocimiento discursivo que tenemos a partir sus argumentos escritos. Ante esto, Gilson responde que están totalmente de acuerdo, puesto que no cree que lo escrito en la Summa agote la comprensión de la vida mística del santo medieval. Con todo, mantiene la tesis de que la obra escrita suponey expresa cognoscitivamente la vida espiritual del autor -junto con su afectividad y sus escalas de valores- y que por ello mismo sirve para revelarnos lo que fue su vida interior.

En suma, estos son los tópicos tratados en las dos cartas que hemos traducido, los cuales, por lo demás, han sido ocasión de numerosos escritos, disputas y reflexiones por parte del tomismo de la pasada centuria. El examen de este intercambio de misivas es una fuente de primer orden para los estudiosos de la historia de la filosofía, y en particular del tomismo del siglo XX. Lo es porque el género epistolar suele liberar a los autores de ciertos protocolos académicos, lo que les permite mostrar su intimidad y auténticos intereses (en este caso filosóficos). En este sentido, nos parece acertada la apreciación de Monsiváis, para quien "en la vida cultural, los epistolarios cumplen una función doble: son el registro más exacto que se conoce del diálogo intelectual, y transforman al interlocutor en espejo de la posteridad" (Monsiváis, 1991: 71).

\footnotetext{
3 "Le platonisme situé la mystique dans le prolongement naturel de la connaissance humaine; dans le thomisme la mystique s'ajoute et se coordonne á la connaissance naturelle, mais elle ne la continué pas".

4 "Saint Thomas, qui situé dans le sensible lobjet propre de lintellect humain, ne considere pas que la fonction la plus haute de notre faculté de connaître consiste á l'étudier. Car cet intellect, qui a pour objet propre le sensible, a pour fonction propre d'en faire de lintelligible". Algunos pasajes del texto francés de El Tomismo, como el aquí citado, ofrecen cierto grado de dificultad para la traducción, por ello en algunas ocasiones nos remitimos a las traducciones españolas ya existentes. Por ejemplo, fuimos a la quinta edición y nos encontramos con el siguiente texto: "Pues este intelecto, cuyo objeto propio es lo sensible, tiene como objeto propio sacar de él algo inteligible" (1951: 507). Si comparamos esta traducción con la inmediatamente anterior veremos que en esta se coloca dos veces la palabra "objeto" cuando en el segundo caso debería decir "función", tal como aparece en el texto francés (fonction). Creemos que la observación se torna relevante si tenemos en cuenta la corrección que introduce el mismo Gilson.
} 
J. Maritain a É. Gilson

† Pax

Versalles, 21 calle Baillet-Reviron,

11 marzo de 1923

Señor,

Hace varios días que quiero escribirle para agradecerle por haberme hecho llegar la nueva edición de vuestro estudio sobre El tomismo. Ocupaciones urgentes me han impedido hacerlo antes.

He leído esta segunda edición con gran interés y he apreciado altamente las adiciones y mejoras hechas al texto de la primera.

Me parece que vuestro estudio responde excelentemente a su subtítulo: introducción al sistema de Santo Tomás de Aquino, y que presenta una exposición muy notable y muy fiel al conjunto de la filosofía del Doctor Angélico. En virtud de esto no he dejado de recomendarlo a los estudiantes de la Universidad de Ginebra, quienes me han pedido el martes pasado que les dictara una conferencia sobre el tomismo.

Estoy particularmente complacido con aquello que usted escribe acerca de la oposición entre las directrices de Santo Tomás y las de Plotino, aunque la fórmula de la página 235 sobre la "negación radical de la mística" me parece aceptable mediando varias aclaraciones. El tomismo no admite ciertamente ninguna intuición natural de Dios por el intelecto creado pero sí admite una intuición sobrenatural de Dios: en el sentido propio de la palabra intuición, si se trata de un raptus, supremo grado de la profecía, (gracia gratis data), que hace participar transitoriamente al alma aquí abajo de la visión beatífica, y en el sentido general de la percepción experiencial, si se trata del conocimiento dado por el don de la Sabiduría, es decir de la contemplación mística o infusa, que es para los tomistas la manifestación normal de la gracia de las virtudes y de los dones.

¿Debería decirle, -pero esta sería una discusión que nos llevaría muy lejos-, que en algunos puntos pienso que no se puede seguir vuestra interpretación? En particular, si Santo Tomás asigna la quidditas rei sensibilis como el objeto connatural del intelecto humano, no creo sin embargo que pudiera decirse que a sus ojos "la función propia del intelecto humano es la constitución de la ciencia" (ciencia en el sentido de lo real sensible). Al menos esta afirmación, en mi opinión, necesitaría ser especialmente matizada. No solamente porque él es un metafísico de raza, sino también porque obedece a su gran principio de que lo inferior está ordenado de suyo a lo superior, de modo que el fin propio del intelecto humano está muy por encima de la función en la cual él se siente más cómodo, y es por eso que especula sobre la esencia divina más de lo que especula sobre el mundo de los cuerpos. Por otra parte, considera la

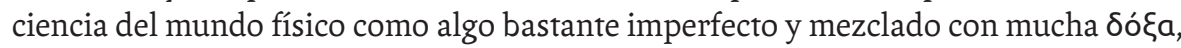
a causa de la materia; por ello el conocimiento claro de las esencias es en este caso muy difícil. Esto lleva a interpretar la quidditas rei sensibilis, en tanto objeto connatural de nuestro intelecto, desde el punto de vista del conocimiento común más que desde el punto de vista de la ciencia...

Además, creo ciertamente como usted que la doctrina filosófica y teológica de Santo Tomás es inseparable de su vida espiritual. Sin embargo, no creo que ella agote esta vida, o que sea suficiente por sí sola para darnos una idea de ella. Precisamente a causa de la noción perfectamente rigurosa que Santo Tomás se hizo de la pureza de 
la disciplina racional y científica, no dejaba que ninguna de sus afecciones penetrara en su obra. Pero su vida mística y su sabiduría permodum inclinationis estaban ciertamente también elevadas muy por encima del conocimiento discursivo y muy ocultas dentro de un amor como el de San Juan de la Cruz.

No vea, Señor, en estas cuantas observaciones sino un testimonio del interés que tengo hacia su trabajo y acepte, se lo ruego, la expresión de mis sentimientos más distinguidos.

J. Maritain

É. Gilson a J. Maritain

6, calle Ponthierry

Melun (S-et-M)

lunes 19 de marzo de 1923

Señor,

Le agradezco muy sinceramente las interesantísimas observaciones que me dirigió y más aún porque las considero completamente fundadas. En la página 235, hay que reemplazar directo por natural y agregar una nota para prevenir al menos acerca de la existencia de una mística tomista. Quizás incluso convenga rehacer el párrafo ya que aquello que distingue al agustinismo del tomismo no es la cuestión de la intuición natural de Dios: ni uno ni el otro la admiten; no es tampoco que "el platonismo encuentra en la mística su último cumplimiento", ya que el tomismo encuentra también allí el suyo; es más bien que el platonismo agustiniano atribuye a nuestro conocimiento normal características que para Santo Tomás serían más bien aquellas del conocimiento místico. Volveré ciertamente sobre este punto.

Igualmente tiene usted razón al criticar la siguiente frase "la función propia del intelecto humano es la constitución de la ciencia". No. El objeto propio del intelecto humano es lo sensible; la función propia del intelecto humano es la de hacerlo inteligible. Y esa es, sin dudas, al par que la presencia del accidente material, la razón que explica la incertidumbre relativa de nuestro conocimiento de las esencias. De todas maneras, es todavía un punto por corregir.

Sobre el tercer punto puede ser que me haya explicado torpemente (la vida interior de Santo Tomás); pero creo que en el fondo mi redacción dice más o menos aquello que usted desearía que diga. Dado que no escribí que la doctrina filosófica y teológica de Santo Tomás agotara su vida espiritual, sino que ella la suponía y expresaba en forma cognoscitiva sus elementos afectivos. Por el contrario, reconozco haber escrito que ella nos basta para darnos una idea y confieso que lo creo; puesto que es cierto que su vida mística y su sabiduría permodum inclinationis estaban muy por encima del conocimiento discursivo. Pero incluyo también en la Summa la mística tal como allí la describe y pienso, en efecto, que el contenido de la Summa nos basta para revelarnos lo que fue la vida interior de aquél que la escribió, con su jerarquía de valores, cada uno de los cuales se define en relación con el resto. Pero comprendo su objeción.

Si mi texto deja creer que Santo Tomás es un intelecto puro hay que corregirlo. Si por otra parte usted cree verdaderamente que en Santo Tomás, el autor de la Summa, hubo más un San Juan de la Cruz, confieso sinceramente que hasta que sea probado (me refiero a hasta que sea persuadido de lo contrario) me resisto a creerlo. Asimismo, 
no lo remitiré a la encantadora edición de De moribus divinis, puesto que usted sabe de quién nos viene, pero ciertamente no es de San Juan de la Cruz. ¿Y sus oraciones? Si él tuvo esta vida escondida, nos la escondió muy bien, pero puede ser también que yo no tenga lo que hace falta para poder verla. Lo digo con toda sinceridad, puesto que no juego con esas cosas.

Espero hacerlo mejor y más en profundidad al estudiar la actitud de Santo Tomás frente a la tradición agustiniana. Créame que le estoy muy agradecido por aquello que me ha escrito; me referiré a ello cuando haya terminado mi San Buenaventura, tan diferente de Santo Tomás pero cuya doctrina posee una belleza que le es peculiar. En varios puntos los comparo el uno con el otro, y a pesar de todos mis esfuerzos por ser exacto, siento que es casi imposible hacer estas comparaciones sin equivocarse. Espero que en ese momento usted me diga si estará disponible.

Le ruego aceptar mis sentimientos distinguidos y mis mayores agradecimientos.

É. Gilson 


\section{Bibliografía}

» Artola, J. M. (1995). “Étienne Gilson-Jacques Maritain: Correspondance 19231971", Revista de Filosofía 13, 181-185.

» Gilson, É. (1922, $2^{\circ}$ ed.). Le Thomisme. Introduction au système de saint Thomas d'Aquin. París: Vrin.

" Gilson, É. (1927, $3^{\circ}$ ed.). Le Thomisme. Introduction au système de saint Thomas d'Aquin. París: Vrin.

"Gilson, É. (1951, $5^{\circ}$ ed.). El Tomismo. Introducción al sistema de Santo Tomás de Aquino. Buenos Aires: Desclée de Brouwer.

"Prouvost, G. (ed.) (1991). Étienne Gilson et Jacques Maritain. Correspondance, 1923-1971. Deux approches de l'être. París: Vrin.

» Monsiváis, C. (1991). El género epistolar: un homenaje a manera de carta abierta. México DF: Porrúa. 
